\title{
VIGILÂNCIA dA QUALIDADE dA ÁGUA PARA CONSUMO HUMANO: ABORDAGEM QUALITATIVA DA IDENTIFICAÇÃO DE PERIGOS
}

\section{DRINKING WATER QUALITY SURVEILLANCE: QUALITATIVE APPROACH OF HAZARD IDENTIFICATION}

ROSE FERRAZ CARMO
Doutoranda em Medicina Veterinária. Departamento de Veterinária - Universidade Federal de Viçosa

PaUla Dias BeVILACQUa

Doutora em Epidemiologia. Departamento de Veterinária - Universidade Federal de Viçosa

RAFAEL KOPSCHITZ XAVIER BASTOS

$\mathrm{PhD}$ em Engenharia Sanitária. Departamento de Engenharia Civil - Universidade Federal de Viçosa

Recebido: 24/07/08 Aceito: 01/10/08

\section{RESUMO}

A necessidade de que os serviços de vigilância da qualidade da água para consumo realizem sistemática/permanente avaliação de risco dos sistemas de abastecimento é um importante desafio. Como a metodologia de Avaliação de Risco ainda não se encontra estruturada para rotineira utilização, apresenta-se uma sugestão de identificação de perigos e categorização de riscos associados ao abastecimento de água, através da utilização da metodologia proposta no Manual de Procedimentos de Vigilância em Saúde Ambiental Relacionada à Qualidade da Água para Consumo Humano, com modificaçōes. Foram identificadas situaçōes de perigo na saída do tratamento e na rede de distribuição do sistema estudado. A aplicação da metodologia permitiu uma visão abrangente do sistema de abastecimento e informaçôes para planejamento/priorização de medidas de forma a reduzir os perigos identificados e possíveis riscos à saúde da população.

PALAVRAS-CHAVE: Vigilância, qualidade da água, identificação de perigos, análise de risco.

\begin{abstract}
Nowadays, an important challenge to the health service is the need of a systematic and permanent drinking water systems risk assessment. The risk analysis methodology is not an easy understanding or applicable tool for the health service routine, so the purpose of this work is a suggestion for the hazard identification and risk categorization associated to the drinking water systems. The methodology proposed in the "Health Environmental Surveillance associated to Drinking Water Quality Manual" was used as reference. Hazard situations were identified also at the treatment exit as at distribution systems studied. The tools for hazard identification and risk categorization proposed are applicable and allowed a general vision of the system. They also are helpful for the planning and the definition of intervention priorities as a way to reduce health risks associated to the drinking water systems.
\end{abstract}

KEYWORDS: Surveillance, water quality, hazard identification, risk analysis.

\section{INTRODUÇÃO}

O termo vigilância pressupõe a avaliação freqüente e continuada de aspectos diversos, objetivando a identificação de riscos potenciais à saúde humana, com vistas a possibilitar formas de intervenção ou controle, assumindo, assim, caráter rotineiro e preventivo. Quando aplicada à qualidade da água para consumo humano, o caráter preventivo torna-se um desafio para os profissionais da vigilância, já que a qualidade da água é dinâmica no tempo e no espaço, sendo o monitoramento realizado ao mesmo tempo em que a água é captada, distribuída e consumida.
A busca por metodologias que permitam a identificação precoce de possíveis riscos à saúde associados a diferentes formas de abastecimento de água, com o intuito de controlar ou minimizar os possíveis impactos à saúde, em tempo hábil, traduz-se, na prática, como um dos grandes desafios para pesquisadores e profissionais que atuam na Vigilância de Qualidade da Água para Consumo Humano. Nesse sentido, a Organização Mundial de Saúde (OMS) recomenda na última edição do Guia para Qualidade da Água de Consumo Humano (WHO, 2004) a utilização da metodologia de Avaliação de Risco, que consiste na caracterização e estimativa, quantitativa ou qualitativa, de potenciais efeitos adversos à saúde devido à exposição de indivíduos e populações a fatores de risco (físicos, químicos e agentes microbianos, ou situações). Essa metodologia é parte constituinte da Análise de Risco, a qual engloba, também, o Gerenciamento de Risco e a Comunicação de Risco (Haas, 1999). A utilização da metodologia de Avaliação de Risco pressupõe quatro etapas fundamentais (i) identificação do perigo, (ii) avaliação da dose-resposta, (iii) avaliação da exposição e (iv) caracterização do risco.

O Guia da OMS ressalta a importância da avaliação e gerenciamento do 
risco durante todo o processo de produção, desde a captação até o consumo, enfatizando a utilização do princípio das múltiplas barreiras, da identificação e gerenciamento de perigos, culminando com a elaboração de um plano preventivo, o Plano de Segurança da Água (WHO, 2004). Sendo assim, a metodologia de Avaliação de Risco é parte integrante de uma cadeia de procedimentos e estratégias para assegurar que o consumidor receba água segura, entretanto a mesma ainda não se encontra estruturada como ferramenta de fácil e rotineira utilização pelos profissionais da vigilância da qualidade da água para consumo humano.

Por outro lado, essa também tem sido a perspectiva adotada nas legislaçôes e instrumentos legais brasileiros que tratam da qualidade da água para consumo humano, conforme explicitado no Inciso VI do Art. 7o da Portaria MS no 518/2004 (Brasil, 2004), que integra o Programa Nacional de Vigilância Ambiental em Saúde relacionada à Qualidade da Água para Consumo Humano (VIGIAGUA):

"são deveres e obrigações das Secretarias Municipais de Saúde (...) efetuar, sistemática epermanentemente, avaliação de risco à saúde humana de cada sistema de abastecimento ou solução alternativa, por meio de informaçôes sobre as caracteristicas fisicas dos sistemas, as práticas operacionais e de controle da qualidade da água, o histórico da qualidade da água produzida e distribuida, a associação entre agravos à saúde e situaçôes de vulnerabilidade do sistema".

O presente trabalho apresenta uma sugestão de abordagem de identificação e categorização de perigos associados aos sistemas de abastecimento de água, tendo como cenário um sistema de abastecimento de um município de médio porte da Zona da Mata Mineira.

\section{Identificação de perigos}

A qualidade da água consumida resulta da qualidade da água bruta, do estado de conservação de equipamentos e instalações da estação e do rigor no controle operacional dos processos de tratamento. Além disso, do tratamento ao consumo, também podem ocorrer as mais variadas interferências e alteraçôes na qualidade da água, ou seja, do ponto de captação da água, no manancial, até o ponto de consumo, no interior da residência, podem ser identificadas diversas situações caracterizadas como perigo.

É importante se fazer a distinção entre perigo e risco. Risco é um conceito que se refere à probabilidade de ocorrência de um evento. A idéia de risco indica a existência de uma associação entre uma exposição e um determinado efeito que, em saúde, poderia ser entendido como óbito, incapacidade, doença ou desordem. Perigo referese a uma característica intrínseca de uma substância ou situação. A água para consumo humano que contenha agentes patogênicos caracteriza um perigo, enquanto seu fornecimento à população traz um risco, que pode ser quantificado e expresso em termos de probabilidade de ocorrência de um agravo, por exemplo, casos de diarréia (Bevilacqua et al, 2002).

Em cada etapa do processo de abastecimento de água podem ser identificadas situações caracterizadas como perigo, podendo expor a população a situações de risco. Conforme descrito no Manual de Procedimentos de Vigilância em Saúde Ambiental Relacionada à Qualidade da Água para Consumo Humano, exemplificam-se algumas situaçôes de perigo: (i) captação de manancial subterrâneo: ausência ou infiltrações no revestimento de poços tubulares; poços situados nas proximidades de sistemas de esgotos e fossas; (ii) captação de manancial superficial: existência de focos de poluição pontuais ou difusos, tais como, ocupação residencial na bacia de captação, atividades agropecuárias e industriais; (iii) tratamento: inadequação da qualidade da água bruta aos processos de tratamento existentes; falhas de projeto ou deficiências de instalações e equipamentos; não atendimento ao plano mínimo de amostragem para o controle da qualidade da água preconizado pela legislação; (iv) reservação: reservatórios em mau estado de conservação, apresentando fendas e, ou, falta de cobertura apropriada; negligência no controle da qualidade da água no interior dos reservatórios; (v) distribuição: serviços intermitentes, acarretando diminuição da pressão ou pressão negativa na rede; estado de conservação precário ou material impróprio da rede; formação de biofilmes (Brasil, 2005).

Em todas as situações apresentadas, é nítida a existência de perigos das mais variadas naturezas e origens que podem expor a população a riscos, notadamente os relacionados aos microrganismos patogênicos e às substâncias/produtos químicos. Essas questôes ressaltam a necessidade de se ampliar a abordagem tradicional que fundamenta a prática do controle da qualidade da água, centrada na coleta e análise de amostras, adotando-se uma visão holística do abastecimento. Nesse sentido, a metodologia de avaliação de risco pode ser útil na tentativa de operacionalizar essa 'nova' abordagem.

\section{OBJETIVO}

Objetivou-se, com o presente trabalho, explorar a proposta de identificação de perigos apresentada no Manual de Procedimentos de Vigilância em Saúde Ambiental Relacionada à Qualidade da Água para Consumo Humano (Brasil, 2005) aplicando-a a um sistema abastecimento de água, com vista à sua avaliação e adaptação.

\section{METODOLOGIA}

\section{Fonte de dados}

Os dados utilizados no trabalho foram disponibilizados pelo Departamento Municipal de Água e Esgoto de um município da Zona da Mata Mineira e se referem ao monitoramento da qualidade da água realizado pelos responsáveis pelo controle. $\mathrm{O}$ município possui cinco diferentes sistemas de abastecimento sendo que o foco do presente trabalho é o sistema denominado ETA I, responsável por fornecer água a $70 \%$ da população residente na área urbana do município. A captação do sistema é realizada em manancial superficial e o tratamento da água é do tipo ciclo completo, com filtração rápida em leito de areia e desinfecção com cloro-gás.

A metodologia utilizada empregou dados referentes ao monitoramento realizado no sistema ETA I, na saída do tratamento e na rede de distribuição, no período de março de 2002 a março de 2004.

\section{Identificação e categorização de perigos}

Para se proceder à identificação e à classificação de perigos e categorização de riscos associados ao abastecimento de água, foi utilizada, como referência, 
a metodologia proposta no Manual de Procedimentos de Vigilância em Saúde Ambiental Relacionada à Qualidade da Água para Consumo Humano, com modificaçōes (Brasil, 2005).

As alterações incorporadas consistiram na inclusão dos itens: (i) atendimento ao plano mínimo de amostragem para os três parâmetros: coliformes totais, turbidez e cloro residual livre (CRL); (ii) atendimento ao padrão bacteriológico para E. coli; (iii) material utilizado na rede de distribuição; (iv) existência de correlação estatisticamente significativa entre a turbidez na saída do tratamento e na rede de distribuição; (v) existência de correlação estatisticamente significativa entre a presença de coliformes totais e $E$. coli e os dados de cloro residual e turbidez na rede de distribuição.

Além disso foram considerados na análise os percentuais de atendimento á legislação naqueles meses onde não houve atendimento integral. Os itens de performance do tratamento e avaliação do flúor proposto pelo Manual de Procedimentos de Vigilância em Saúde Ambiental Relacionada à Qualidade da Água para Consumo Humano não foram considerados por não haver dados disponíveis.

A metodologia foi dividida em duas etapas: a primeira refere-se à identificação e a classificação de acordo com a presença ou ausência de perigos, a segunda diz respeito à categorização do grau de risco que o sistema de abastecimento ETA I oferece para população.

$\mathrm{Na}$ primeira etapa foram avaliados aspectos relacionados ao padrão de potabilidade exigido pela legislação e aspectos de caráter geral, descritos a seguir:

a) Aspectos relacionados ao padrão de potabilidade exigido pela legislação, para saída do tratamento e rede de distribuição:

- atendimento ao plano mínimo de amostragem para os parâmetros: coliformes totais, turbidez e CRL. Os resultados foram avaliados em termos de meses nos quais não foi atendido o plano mínimo de amostragem preconizado na Portaria MS no 518/2004 (Brasil, 2004) em relação ao número total de meses estudados, além dos percentuais de atendimento observados naqueles meses onde não houve atendimento integral.

- avaliação da qualidade da água (coliformes totais e E. coli): os resultados foram avaliados, anualmente, em termos de percentual de não atendimento ao padrão de potabilidade (complemento do índice bacteriológico), além dos percentuais de atendimento observados naqueles meses nos quais não houve atendimento integral.

- avaliação da qualidade da água (turbidez e CRL): aqui também os resultados foram avaliados, anualmente, em termos de percentual de não atendimento ao padrão de potabilidade (complemento do índice de turbidez e do índice de cloro residual livre), além dos percentuais de atendimento observados naqueles meses nos quais não houve atendimento integral.

b) Aspectos de caráter geral relacionados à adequabilidade do tratamento, estado de conservação da rede e existência de correlações entre parâmetros analisados:

- tipo de manancial e de técnica de tratamento: neste item procurou-se avaliar a adequabilidade do processo de tratamento, levando em consideração o tipo de manancial. Foram adotadas as exigências da Portaria MS no 518/2004 (Brasil, 2004), conforme Art. 22 (toda água fornecida coletivamente deve ser submetida ao processo de desinfecção, concebido e operado de forma a garantir o atendimento ao padrão microbiológico exigido) e Art. 23 (toda água para consumo humano suprida por manancial superficial e distribuída por meio de canalização deve incluir tratamento pro filtração);

- informações sobre o material utilizado na rede de distribuição: foi considerado neste item o material de constituição das tubulaçôes da rede de distribuição. Sendo que a rede de distribuição constituída por PVC foi considerada adequada e a rede constituída por algum outro tipo de material como ferro fundido, por exemplo, foi considerada inadequada;

- existência de correlação estatisticamente significativa entre a turbidez na saída do tratamento e na rede de distribuição: de modo a inferir sobre a eficiência do tratamento e a possibilidade de eventual recontaminação na rede de distribuição;

- existência de correlação estatisticamente significativa entre a presença de coliformes totais e $E$. coli e os dados de cloro residual e turbidez na rede de distribuição: de modo a inferir sobre a correlação entre presença de coliformes totais e valores de trubidez e cloro residual na rede de distribuição.

Para se proceder a avaliação dos itens relativos ao atendimento ao plano mínimo de amostragem e atendimento ao padrão de potalidade para os parâmetros (coliformes totais, E. coli, CRL e turbidez), exigido pela Portaria MS no 518/2004 (Brasil, 2004), foram calculados: índices de coleta, índice bacteriológico, índice de turbidez e índice de CRL, de acordo com as equaçôes a seguir:
$\mathrm{IC}(\%)=\frac{\mathrm{N}^{\circ} \text { de amostras coletadas nas diversas partes do sistema de abastecimento }}{\mathrm{N}^{\circ} \text { de amostras a coletar segundo os planos de amostragem }} \times 100$

da Portaria MS n ${ }^{\circ}$ 518/2004

$\operatorname{IB}(\%)=\frac{\mathrm{N}^{\circ} \text { de amostras com ausên cia de coliformes }}{\mathrm{N}^{\circ} \text { de amostras coletadas }} \times 100$

$\operatorname{IT}(\%)=\frac{\mathrm{N}^{\circ} \text { de amostras de acordo com o padrãode turbidez }}{\mathrm{N}^{\circ} \text { de amostras coletadas }} \times 100$

$\operatorname{ICRL}(\%)=\frac{\mathrm{N}^{\circ} \text { de amostras de acordo com o padrão de CRL }}{\mathrm{N}^{\circ} \text { de amostras coletadas }} \times 100$ 
Em um primeiro momento, cada item foi avaliado mensalmente, ou seja, os índices calculados (índices de coleta, índice bacteriológico, índice de turbidez e índice de CRL) referem-se a cada um dos meses de análise (março de 2002 a março de 2004). Posteriormente, os dados foram agregados por ano, para elaboração dos respectivos índices.

Para efeitos de interpretação, de acordo com a Portaria MS no 518/2004, os índices de coleta, turbidez e CRL mínimos exigidos são de 100\%. Para o índice bacteriológico, no caso de sistemas que analisam 40 ou mais amostras por mês, o IB mínimo aceitável mensal é de 95\% (Brasil, 2004). Ainda conforme essa legislação, os planos de amostragem mínimos para o sistema em estudo, baseado na população abastecida, seria o descrito na Tabela 1.

Os dados de turbidez na saída do tratamento e na rede de distribuição foram utilizados em estudos de correlação, sendo inicialmente testados para normalidade pelo teste D' Agostino e, posteriormente, calculados o coeficiente de correlação de Spearman $\left(\mathrm{r}_{\mathrm{s}}\right)$ e o valor de $\mathrm{p}$ correspondente. Como as variáveis coliformes totais e $E$. coli estavam expressas no banco de dados como variáveis qualitativas, as análises de correlação entre essas e as variáveis CRL e turbidez foram realizadas a partir da construção de tabelas de contingência $(2 \times 2)$. Às variáveis coliformes totais e E. coli foram atribuídas as categorias presença ou ausência e às variáveis CRL e turbidez, atendem ou não atendem ao padrão de potabilidade $(0,2 \mathrm{mg} / \mathrm{L}$ para CRL e 5 uT para turbidez). A correlação foi analisada a partir do cálculo do Coeficiente Phi $\left(\mathrm{r}_{\varnothing}\right)$, do valor de p e do respectivo coeficiente de determinação $\left(\mathrm{R}^{2}\right)$. Todas as análises de correlação foram realizadas no programa BioEstat 2.0 (Ayres et al, 2000) e interpretadas considerando o nível de significân-cia de $5 \%$. A metodologia de avaliação de risco pressupóe o estabelecimento de critérios de aceitabilidade para o desempenho dos aspectos analisados, procurando-se associá-los a uma consequiência positiva ou negativa para a saúde da população. Nesse sentido, optou-se pela categorização de cada item avaliado, anualmente, de acordo com o grau de perigo que representavam para o sistema de abastecimento estudado, uma vez que, na análise, não foram considerados aspectos relativos à ocorrência de agravos na população.

Tabela I - Frequência mínima de amostragem para o controle da qualidade da água do sistema de abastecimento ETA I, março de 2002 a março de 2004

\begin{tabular}{|c|c|c|c|c|}
\hline \multirow[t]{2}{*}{ Parâmetro } & \multicolumn{2}{|c|}{$\begin{array}{c}\text { Saída do Tratamento } \\
\text { ETA I }{ }^{(1)}\end{array}$} & \multicolumn{2}{|c|}{$\begin{array}{c}\text { Rede de Distribuição } \\
\text { ETA I }\end{array}$} \\
\hline & Número & Frequência & Número & Frequência \\
\hline Turbidez & 1 & $\begin{array}{l}\text { a cada duas } \\
\text { horas }\end{array}$ & 14 & mensal \\
\hline Cloro residual livre & 1 & $\begin{array}{l}\text { a cada duas } \\
\text { horas }\end{array}$ & 64 & mensal \\
\hline Coliformes & 2 & Semanal & 64 & mensal \\
\hline
\end{tabular}

Nota: (1) A ETA I abastece, aproximadamente, $70 \%$ da população da área urbana do distrito sede. Considerando os dados do Censo Demográfico de 2001 (IBGE, 2005), a população estimada abastecida por esse sistema é de 67.128 habitantes.

Para realizar a categorização dos perigos identificados foram utilizadas tonalidades de cor cinza, que significavam situaçóes de presença ou ausência de perigo.

- Cinza claro: situação de ausência de perigo

- Cinza escuro: situação de presença de perigo

A Tabela 2 relaciona os critérios adotados para categorizaçáo de cada um dos itens avaliados.

Após a primeira etapa de identificação e classificação segundo a ausência (cinza claro) ou presença (cinza escuro) de perigos, foi realizada a segunda etapa, a qual consistiu na categorização do grau de risco que o sistema representa para população. Foram utilizadas três categorias cinza claro (baixo risco), hachurado (médio risco) e cinza escuro (alto risco). Os critérios adotados foram:

Cinza claro $=$ baixo risco

- tratamento adequado às características do manancial;

- bom estado de conservação da rede de distribuição;

- melhoria ou situação igual do parâmetro bacteriológico de um período em relação a outro, considerando o atendimento à legislação;

- melhoria ou situação igual de pelo menos 3 dos 4 parâmetros analisados (coliformes totais, E. coli, CRL, turbidez), considerando a saída do tratamento e a rede de distribuição, quanto ao percentual de não atendimento ao padrão exigido, em relação ao total de amostras analisadas de um período em relação ao outro;

- melhoria ou situação igual de pelo menos 2 dos 3 parâmetros analisados (coliformes totais, turbidez e CRL), considerando a saída do tratamento e a rede de distribuição, quanto ao per- centual de não atendimento ao plano mínimo de amostragem exigido, em relação ao número de meses analisados de um período em relação ao outro;

- ausência de correlação estatisticamente significativa entre valores de turbidez na saída do tratamento e na rede de distribuição;

- ausência de correlação estatisticamente significativa entre a presença de coliformes totais e os parâmetros (E. coli , CRL e turbidez na rede de distribuição);

- o não atendimento de um dos critérios acima classifica o sistema como risco médio "hachurado".

Hachurado = médio risco

- tratamento adequado às características do manancial;

- bom estado de conservação da rede de distribuição; mesmo com restrições;

- melhoria ou situação igual do parâmetro bacteriológico de um período em relação a outro, considerando o atendimento à legislação;

- melhoria ou situação igual de pelo menos 2 dos 4 parâmetros analisados (coliformes totais, E. coli, CRL, turbidez), considerando a saída do tratamento e a rede de distribuição, quanto ao percentual de não atendimento ao padrão exigido, em relação ao total de amostras analisadas de um período em relação ao outro;

- melhoria ou situação igual de pelo menos 1 dos 3 parâmetros analisados (coliformes totais, turbidez e CRL), considerando a saída do tratamento e a rede de distribuição, quanto ao percentual de não atendimento ao plano mínimo de amostragem exigido, em relação ao número de meses analisados de um período em relação ao outro;

- ausência de correlação estatisticamente significativa entre valores de 
Tabela 2 - Categorização dos itens avaliados segundo a presença ou ausência de perigo

Aspectos relacionados ao padrão de potabilidade

Item avaliado

Saída do tratamento

Rede de distribuição

Atendimento ao plano mínimo de

amostragem (turbidez, CRL, coliformes totais)

Avaliação da qualidade bacteriológica da água: coliformes totais

Cinza claro - atende

Cinza escuro - não atende

Cinza claro - ausência em 100\% das amostras

Cinza escuro - presença

Avaliação da qualidade bacteriológica da água: $E$. coli

Avaliação da qualidade da água: turbidez

Avaliação da qualidade da água: $\mathrm{CRL}^{(1)}$

\author{
Cinza claro - ausência em 100\% \\ das amostras \\ Cinza escuro - presença \\ Cinza claro - atendimento em 100\% \\ das amostras \\ Cinza escuro - não atendimento
}

Cinza claro - atendimento em 100\%

Cinza escuro - não atendimento
Cinza claro - atende

Cinza escuro - não atende

Cinza claro - ausência em 95\% das amostras

Cinza escuro - presença em mais do que $5 \%$ das amostras

Cinza claro - ausência em

$100 \%$ das amostras

Cinza escuro - presença

Cinza claro - atendimento em 100\% das amostras

Cinza escuro - não atendimento

Cinza claro - atendimento em $100 \%$ das amostras

Cinza escuro - não atendimento

Aspectos de caráter geral

Tipo de manancial e de técnica de tratamento

Material utilizado na rede de distribuição

Correlação estatisticamente significativa entre turbidez na saída do tratamento e na rede de distribuição

Correlação estatisticamente significativa entre presença de coliformes totais e E. coli e os dados de CRL e turbidez na rede de distribuição
Cinza claro: adequado

Cinza escuro: não adequado Cinza claro: adequado (tubulações de PVC)

Cinza escuro: não adequado

Cinza claro: ausência de correlação

Cinza escuro: existência de correlação

Cinza claro: ausência de correlação

Cinza escuro: existência de correlação turbidez na saída do tratamento e na rede de distribuição;

- ausência de correlação estatisticamente significativa entre a presença de coliformes totais e pelo menos 2 dos parâmetros (E. coli CRL e turbidez) na rede de distribuição;

- o não atendimento de um dos critérios acima classifica o sistema como alto risco "cinza escuro".

Cinza escuro $=$ alto risco

- tratamento inadequado às exigências do manancial;

- estado de conservação da rede comprometido;

- piora do parâmetro bacteriológico de um período em relação ao outro, considerando o atendimento à legislação;

- melhoria ou situação igual de pelo menos 1 dos 4 parâmetros analisados (coliformes totais, E. coli, CRL, turbidez), considerando a saída do tratamento e a rede de distribuição, quanto ao percentual de não atendimento ao padrão exigido, em relação ao total de amostras analisadas de um período em relação ao outro;

- piora ou não alteração dos parâmetros analisados (coliformes totais, turbidez e CRL), considerando a saída do tratamento e a rede de distribuição, quanto ao percentual de não atendimento ao plano mínimo de amostragem exigido, em relação ao número de meses analisados de um período em relação ao outro;

- existência de correlação estatisticamente significativa entre valores de turbidez na saída do tratamento e na rede de distribuição;

- ausência de correlação estatisticamente significativa entre a presença de coliformes totais e pelo menos um dos parâmetros (E. coli, CRL e turbidez) na rede de distribuição.

Destaca-se que, para a presente análise, os itens foram avaliados anualmente, todavia, deve-se considerar a possibilidade de alteração da frequência de análise, de acordo com a necessidade do serviço de vigilância. Desta forma, para uma melhor caracterização da situação de cada sistema de abastecimento e implementação ágil de medidas corretivas e preventivas, a avaliação pode ser, por exemplo, mensal ou, até mesmo, semanal.

\section{RESULTADOS}

\section{Aspectos relacionados ao padrão de potabilidade}

A classificação dos perigos identificados com tonalidades de cor, presença (cinza escuro) ou ausência (cinza claro), está apresentada na Tabela 3. De forma complementar, é interessante observar, no que se refere ao plano mínimo de amostragem e ao padrão de potabilidade para os parâmetros físicos e químicos (CRL e turbidez), os percentuais de 
amostras que não cumprem o padrão de potabilidade observados naqueles meses nos quais não houve atendimento integral (100\%) ao preconizado pela Portaria MS no 518/2004 e, no que se refere ao parâmetro microbiológico (coliformes totais e E. coli), os percentuais de presença desses organismos indicadores de forma a direcionar prioridades na aplicação de medidas corretivas e preventivas.

\section{Atendimento ao plano mínimo de amostragem}

A avaliação do cumprimento ao plano mínimo de amostragem definido na Portaria MS no 518/2004 é relevante, uma vez que o monitoramento, em número e frequência adequados, dos parâmetros preconizados na legislação permite melhores inferências sobre a qualidade da água. Considerando a definição de perigo como uma característica intrínseca de uma substância ou de uma situação o não atendimento aos planos mínimos de amostragem pode se configurar como tal, na medida em que compromete o monitoramento (situação) e pode ocultar outras situações de perigo relacionadas à qualidade da água tratada e distribuída (por exemplo, presença de contaminação).

Dessa forma, os resultados apresentados na Tabela 3 apontam para uma situação de perigo bastante nítida, uma vez que o atendimento integral ao exigido pela legislação foi observado apenas para coliformes totais, na saída do tratamento. Situação ainda mais crítica foi observada na rede de distribuição onde o percentual de não atendimento alcançou 100\% para coliformes totais.

Considerando a evolução do atendimento ao plano mínimo de amostragem durante o período de estudo, na saída do tratamento houve melhora gradual de dois parâmetros: turbidez e CRL, partindo ambos de percentuais de não atendimento iguais a $60 \% \mathrm{em}$ 2002, para 33,3\% em 2003 alcançando $0 \%$ em 2004, ou seja, atendimento integral. No entanto, na rede de distribuição houve melhora apenas do parâmetro turbidez e piora gradativa dos parâmetros CRL e coliformes totais, os quais atingiram percentual de $100 \%$ de não atendimento no ano de 2004.

Como já indicado anteriormente, a falta de monitoramento adequado implica na dificuldade de garantir que a população esteja sendo abastecida com água segura para o consumo.

\section{Avaliação da qualidade da água}

A avaliação da qualidade da água revelou também a existência de perigos nítidos, sobretudo com relação aos parâmetros físicos e químicos (turbidez e CRL) que não apresentaram atendimento integral às exigências da legislação em nenhum dos períodos analisados (Tabela 3). Considerando o parâmetro turbidez, houve uma redução dos percentuais de não atendimento entre 2002 e 2004, na saída do tratamento $(83,6 \%$ para $59,3 \%)$ e na rede de distribuição $(21,5 \%$ para $0,8 \%)$. A diferença nos percentuais de não atendimento observada entre os dois pontos de monitoramento, pode ser explicada pelo fato de que o padrão exigido para saída do tratamento (1 uT) é mais restritivo do que para a rede de distribuição ( $5 \mathrm{uT}$ ). Entretanto, ainda que a evolução observada sinalize uma melhora da qualidade da água, é importante ressaltar que valores elevados de turbidez devem ser sempre entendidos como perigo, sobretudo quando referendados pela ocorrência de coliformes totais e E. coli (Tabela 3). Adicionalmente, valores elevados de turbidez podem implicar em rejeição pelo consumidor.

O parâmetro CRL apresentou, no período, aumento nos percentuais de não atendimento na saída do tratamento $(0,03 \%$ para $6,5 \%)$ e redução na rede de distribuição (20,8\% para $3,9 \%)$. Ainda que esse último caso indique melhora no atendimento ao padrão de potabilidade (mínimo de $0,2 \mathrm{mg} / \mathrm{L}$ ), podem ser identificados perigos relacionados à dificuldade de manutenção do CRL na rede de distribuição desse sistema.

Com relação à qualidade bacteriológica da água, na saída do tratamento foi detectada presença de coliformes totais em dois dos períodos analisados, indicando falhas ou insuficiência no tratamento. No entanto, nota-se uma melhora no atendimento ao padrão microbiológico na saída do tratamento (ausência de coliformes totais), já que em 2004 não foram identificadas amostras positivas. $\mathrm{Na}$ rede de distribuição, também foram encontradas amostras positivas para coliformes totais acima do preconizado pela legislação (presença em mais de 5\% das amostras analisadas mensalmente). A avaliação da evolução desse parâmetro demonstrou redução dos percentuais de não atendimento entre 2002 e 2003 (13,0\% para 3,6\%), entretanto, entre 2003 e 2004 ocorreu aumento (3,6\% para 9,8\%). A detecção de coliformes totais na rede de distribuição não guarda uma relação conclusiva com contaminação ou recontaminação de origem fecal, assim, a detecção eventual de coliformes totais no sistema de distribuição, em um percentual das amostras analisadas (5\%), não necessariamente é indicativa de contaminação. Por outro lado, coliformes totais servem como indicador da integridade do sistema de distribuição, como, por exemplo, ocorrência de infiltraçôes e rupturas na rede, podendo resultar em contaminação da água, nesse sentido, amostras positivas podem significar situações de perigo (Brasil, 2006). Na saída do tratamento não foram encontradas amostras positivas para E. coli, havendo atendimento integral, para todo período analisado, ao preconizado pela Portaria MS no 518/2004. Em contrapartida, na rede de distribuição, em 2002, foram encontradas $0,43 \%$ de amostras positivas para $E$. coli, sinal inequívoco de recontaminação ou falhas no tratamento. Essa situação corresponde a um perigo ainda mais nítido, uma vez que sendo esse indicador de origem exclusivamente fecal, sua relação com a ocorrência de organismos patogênicos é evidente. Nos anos 2003 e 2004, não foram encontradas amostras positivas para $E$. coli na rede de distribuição, havendo, portanto, atendimento pleno à legislação.

\section{Aspectos de caráter geral}

Tipo de manancial e de tecnologia de tratamento

O sistema ETA I, suprido por manancial superficial, operava em ciclo completo de tratamento, incluindo as etapas de 2 coagulação, floculação, sedimentação, filtração e desinfecção, atendo aos Art. 22 e Art. 23 da Portaria MS no 518/2004 (Brasil, 2004).

Estado de conservação da rede de distribuição

A rede de distribuição do sistema ETA I era constituída por ferro fundido, em algumas áreas mais antigas, determinando o aparecimento de incrustações de ferro e manganês. Apesar de não existirem evidências de efeitos deletérios ao organismo, a presença desses compo- 
nentes pode ocasionar rejeição da água pelo consumidor, devido à coloração acastanhada que confere à água, além de manchar louças de sanitários e roupas. Como essa situação foi verificada apenas em alguns pontos mais antigos, o estado de conservação da rede foi considerado adequado, mas com restriçốes.

Correlação estatisticamente significativa entre turbidez na saída do tratamento e na rede de distribuição

Testes estatísticos não indicaram correlação entre os valores de turbidez na saída do tratamento e na rede de distribuição ( $\left.p=1,000 ; r_{s}=0,3725\right)$. Portanto, a presença de valores mais elevados de turbidez na rede de distribuição pode ser devido ao tipo de material constitutivo das tubulaçôes (ferro fundido em algumas partes mais antigas do trajeto). De qualquer forma, é relevante manter a perspectiva de que valores elevados de turbidez devem ser sempre entendidos como perigo.

Correlação estatisticamente significativa entre presença de coliformes totais e E. coli e os dados de CRL e turbidez na rede de distribuição

Como não foram detectadas amostras positivas para $E$. coli nos anos de 2003 e 2004, a análise de correlação dessa variável com as demais não foi realizada. As tentativas de correlação entre as variáveis não apresentaram resultados estatisticamente significativos, com exceção dos dados de CRL na rede de distribuição e a presença ou ausência de amostras positivas para coliformes totais; entretanto, mesmo nesse caso, apenas $16 \%$ da variação de amostras positivas ou negativas encontradas para coliformes totais pode ser explicada pela variação nos valores de CRL ou vice-versa $\left(r_{\varnothing}=0,4000 ; R^{2}=0,16 ; p<0,01\right)$. No entanto, o sentido dessa correlação não parece coerente, uma vez que foi positiva, significando que à medida que aumenta CRL aumenta a presença de coliforme, sendo que a expectativa seria de uma correlação negativa. Sendo assim, a mesma não foi considerada válida na categorização desse item (Tabela 3).

A análise dos dados apresentados permite classificar o sistema ETA I no grau de médio risco. A Tabela 4 apresenta um resumo dos critérios adotados para essa classificação.
A avaliação da Tabela 4 demonstra, de forma clara e didática, problemas identificados no sistema ETA I. Assim, na saída do tratamento: não cumprimento do plano mínimo de amostragem para os parâmetros turbidez e CRL, com melhoria nos percentuais de atendimento de ambos, e não adequação da qualidade bacteriológica da água com relação aos parâmetros coliformes totais, turbidez e CRL, sendo que para os dois primeiros houve aumento dos percentuais de amostras que atendiam ao padrão de potabilidade e para o último, redução. $\mathrm{Na}$ rede de distribuição: não cumprimento do plano mínimo de amostragem para todos os parâmetros, com melhoria apenas da turbidez, e não adequação da qualidade bacteriológica para coliformes totais, E. coli, turbidez e CRL, com aumento dos percentuais de amostras que atenderam ao padrão de potabilidade para os três últimos. Com relação aos aspectos de caráter geral, o sistema ETA I apresentou problemas no item 'estado de conservação da rede de distribuição'.

A caracterização do sistema dessa forma permite uma visão geral do mesmo, além de dados e informações importantes para o planejamento e priorização de medidas corretivas de forma a reduzir os perigos identificados e possíveis riscos à saúde da população consumidora associados.

\section{CONCLUSÕES}

A necessidade, explicitada na Portaria MS no 518/2004, de que os serviços de vigilância da qualidade da água para consumo realizem sistemática e permanente avaliação de risco de cada sistema de abastecimento de água é um importante desafio ao setor saúde. Nesse sentido, reside a principal contribuição deste trabalho: a sugestão de uma abordagem de identificação de perigos e categorização do grau de risco associado aos sistemas de abastecimento de água, incorporando elementos da metodologia de Avaliação de Risco e trazendo subsídios importantes para a atuação da vigilância junto aos responsáveis pelo controle da qualidade da água, nas diferentes esferas de governo.

A aplicação da metodologia de identificação e classificação de perigos e categorização do grau de risco permitiu uma visão abrangente da realidade do sistema de abastecimento estudado, apontando prioridades em termos de ação da vigilância e dos responsáveis pelo sistema.

Recomenda-se a continuidade de estudos nesse sentido, inclusive no aperfeiçoamento e validação da referida proposta, de forma a facilitar e desenvolver, em pleno potencial, as açôes de vigilância da qualidade da água para consumo humano no país.

\section{AGRADECIMENTOS}

Os/as autores/as agradecem o apoio financeiro recebido da Fundação de Amparo à Pesquisa do Estado de Minas Gerais (FAPEMIG) e as bolsas de apoio técnico à pesquisa concedidas pela FAPEMIG e pelo Conselho $\mathrm{Na}$ cional de Desenvolvimento Científico e Tecnológico (CNPq).

\section{REFERÊNCIAS}

AYRES M. et al. BioEstat 2.0 Aplicaçōes estatísticas nas áreas das ciências biológicas e médicas. Belém/ Brasília : Sociedade Civil Mamirauá/CNPq; 2000.

BEVILACQUA PD et al. Densidades de Giardia e Cryptosporidium em mananciais de abastecimento de água e prevalência de giardiase: usos e aplicações do modelo teórico de avaliação de risco .[CD-ROM] Anais do XXVIII Congresso Interamericano de Engenharia Sanitária e Ambiental. Cancun: Associação Interamericana de Engenharia Sanitária e Ambiental; 2002.

BRASIL. MINISTÉRIO DA SAÚDE. Manual de procedimentos de vigilancia em saúde ambiental relacionada à qualidade da água para consumo humano. Brasília: Ministério da Saúde; 2006.

BRASIL. MINISTÉRIO DA SAÚDE. Portaria no. 518. Estabelece os procedimentos e responsabilidades relativos ao controle e vigilância da qualidade da água para consumo humano e seu padrão de potabilidade, e dá outras providências. Diário Oficial da União; 26 mar. 2004.

FUNDAÇÃO INSTITUTO BRASILEIRO DE GEOGRAFIA E ESTATÍSTICA. Censo demográfico 2000. http://www.ibge.gov.br (acessado em 05/Mai/2005).

HAAS C, N. Risk assessment paradigms. In: Quantitative microbial risk assessment. New York: John Wiley \& Sons, p. 86-106, 1999.

WORLD HEALTHORGANIZATION. Guidelines for drinking water quality. Geneva: WHO; 2004.

Endereço para correspondência:
Paula Dias Bevilacqua
Departamento de Veterinária
Universidade Federal de Viçosa
Campus Universitário
36570-000 Viçosa - MG - Brasil
Tel.: (3I) 3899-I467
E-mail: paula@ufv.br 
Tabela 3 - Categorização dos itens avaliados, segundo a ausência ou presença de perigos, sistema de abastecimento ETA I, saída do tratamento e rede de distribuição, município da Zona da Mata Mineira, março de 2002 a março de 2004

\begin{tabular}{|c|c|c|c|c|c|c|}
\hline \multicolumn{7}{|c|}{ Aspectos relacionados ao padrão de potabilidade ${ }^{(1)}$} \\
\hline \multirow[t]{2}{*}{ Item avaliado } & \multicolumn{3}{|c|}{ Saída do tratamento } & \multicolumn{3}{|c|}{ Rede de distribuição } \\
\hline & 2002 & 2003 & 2004 & 2002 & 2003 & 2004 \\
\hline $\begin{array}{l}\text { Atendimento ao plano mínimo de } \\
\text { amostragem: turbidez }\end{array}$ & $\begin{array}{l}60 \% \\
\mathrm{NA}^{(2)}\end{array}$ & $\begin{array}{l}33 \% \\
\text { NA }\end{array}$ & $\begin{array}{l}0 \% \\
\text { NA }\end{array}$ & $\begin{array}{l}20 \% \\
\text { NA }\end{array}$ & $\begin{array}{l}0 \% \\
\text { NA }\end{array}$ & $\begin{array}{l}0 \% \\
\mathrm{NA}\end{array}$ \\
\hline Atendimento ao plano mínimo de amostragem: CRL & $\begin{array}{l}60 \% \\
\mathrm{NA}\end{array}$ & $\begin{array}{l}33,3 \% \\
\text { NA }\end{array}$ & $\begin{array}{l}0 \% \\
\text { NA }\end{array}$ & $\begin{array}{l}70 \% \\
\text { NA }\end{array}$ & $\begin{array}{l}91,8 \% \\
\text { NA }\end{array}$ & $\begin{array}{l}100 \% \\
\text { NA }\end{array}$ \\
\hline $\begin{array}{l}\text { Atendimento ao plano mínimo de } \\
\text { amostragem: coliformes totais }\end{array}$ & $\begin{array}{l}0 \% \\
\text { NA }\end{array}$ & $\begin{array}{l}0 \% \\
\text { NA }\end{array}$ & $\begin{array}{l}0 \% \\
\text { NA }\end{array}$ & $\begin{array}{l}70 \% \\
\text { NA }\end{array}$ & $\begin{array}{l}91,8 \% \\
\text { NA }\end{array}$ & $\begin{array}{l}100 \% \\
\text { NA }\end{array}$ \\
\hline $\begin{array}{c}\text { Avaliação da qualidade bacteriológica da } \\
\text { água: coliformes totais }\end{array}$ & $\begin{array}{c}0,95 \% \\
\text { presença }^{(3)}\end{array}$ & $\begin{array}{l}2,5 \% \\
\text { presença }\end{array}$ & $\begin{array}{c}0 \% \\
\text { presença }\end{array}$ & $\begin{array}{c}13 \% \\
\text { presença }\end{array}$ & $\begin{array}{c}3,6 \% \\
\text { presença }\end{array}$ & $\begin{array}{c}9,8 \% \\
\text { presença }\end{array}$ \\
\hline Avaliação da qualidade bacteriológica da água: E. coli & $\begin{array}{c}0 \% \\
\operatorname{presença~}^{(4)}\end{array}$ & $\begin{array}{c}0 \% \\
\text { presença }\end{array}$ & $\begin{array}{l}0 \% \\
\text { presença }\end{array}$ & $\begin{array}{c}0,43 \% \\
\text { presença }\end{array}$ & $\begin{array}{c}0 \% \\
\text { presença }\end{array}$ & $\begin{array}{c}0 \% \\
\text { presença }\end{array}$ \\
\hline $\begin{array}{c}\text { Avaliação da qualidade bacteriológica da } \\
\text { água: turbidez }\end{array}$ & $\begin{array}{c}83,6 \% \\
\text { NA }\end{array}$ & $\begin{array}{l}47,5 \% \\
\text { NA }\end{array}$ & $\begin{array}{l}59,3 \% \\
\text { NA }\end{array}$ & $\begin{array}{l}21,5 \% \\
\mathrm{NA}\end{array}$ & $\begin{array}{c}13,8 \% \\
\text { NA }\end{array}$ & $\begin{array}{l}0,8 \% \\
\text { NA }\end{array}$ \\
\hline Avaliação da qualidade bacteriológica da água: CRL & $\begin{array}{l}0,03 \% \\
\text { NA }\end{array}$ & $\begin{array}{l}0,92 \% \\
\text { NA }\end{array}$ & $\begin{array}{l}6,5 \% \\
\mathrm{NA}\end{array}$ & $\begin{array}{l}20,8 \% \\
\text { NA }\end{array}$ & $\begin{array}{l}21,8 \% \\
\text { NA }\end{array}$ & $\begin{array}{l}3,9 \% \\
\mathrm{NA}\end{array}$ \\
\hline Item avaliado & \multicolumn{6}{|c|}{ Aspectos de caráter geral } \\
\hline \multicolumn{7}{|l|}{ Tipo de manancial e de técnica de tratamento } \\
\hline \multicolumn{7}{|l|}{ Estado de conservação da rede de distribuição } \\
\hline \multicolumn{7}{|l|}{$\begin{array}{l}\text { Correlação estatisticamente significativa entre } \\
\text { turbidez na saída do tratamento e na rede } \\
\text { de distribuição }\end{array}$} \\
\hline \multicolumn{7}{|l|}{$\begin{array}{c}\text { Correlação estatisticamente significativa entre } \\
\text { presença de coliformes totais e turbidez na rede } \\
\text { de distribuiçãa }\end{array}$} \\
\hline $\begin{array}{c}\text { Correlação estatisticamente significativa entre } \\
\text { presença de coliformes totais e CRL na rede } \\
\text { de distribuição }\end{array}$ & & & & & & \\
\hline
\end{tabular}

Notas: ${ }^{(1)}$ cinza claro (baixo risco) e cinza escuro (alto risco). ${ }^{(2)}$ Percentual de não atendimento à legislação. ${ }^{(3)}$ Percentual de presença de coliformes totais. ${ }^{(4)}$ Percentual de presença de E. coli. 
Tabela 4 - Classificação final do sistema ETA I segundo critérios adotados para categorização do grau de risco

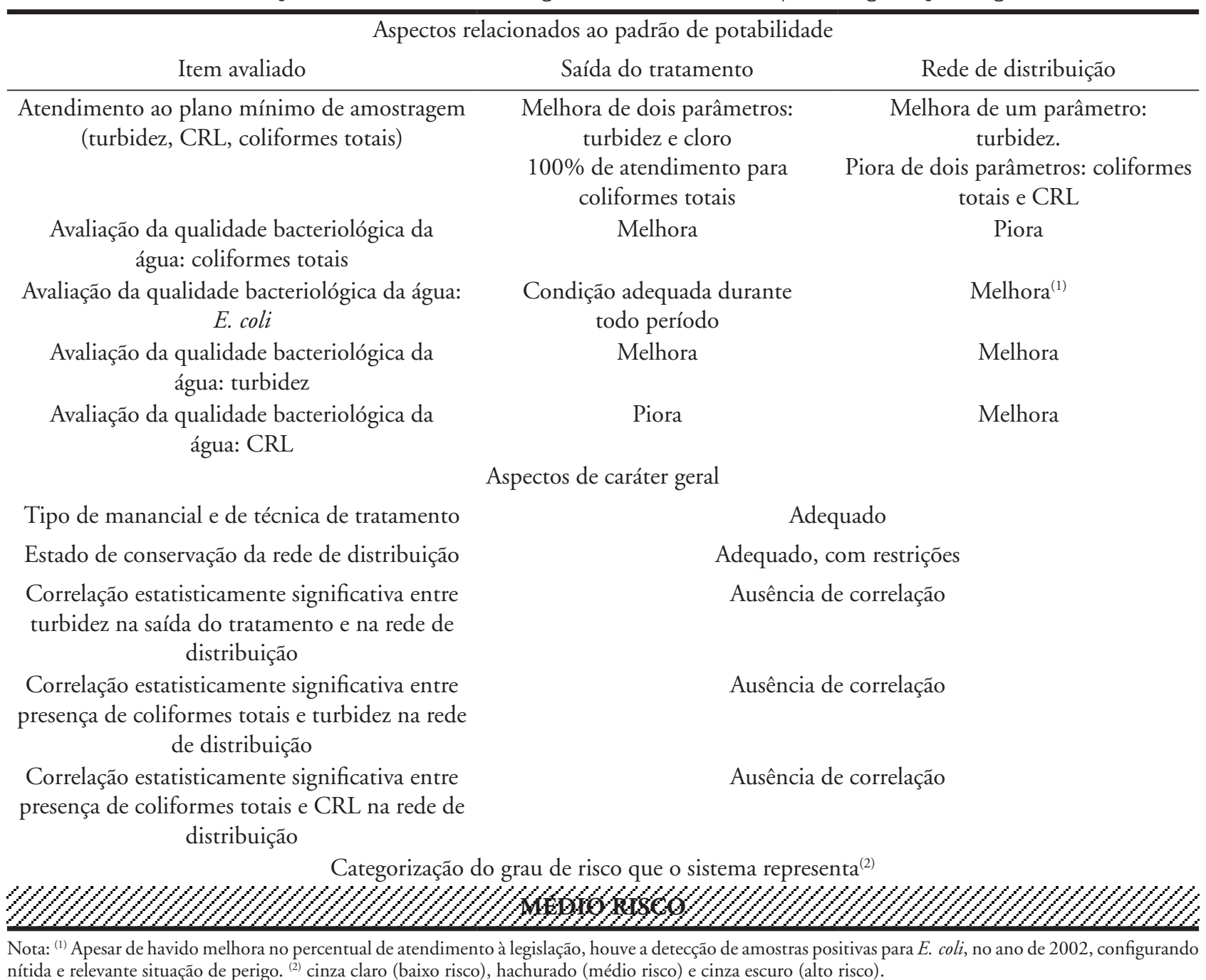

